\title{
Obituary
}

\section{Leon Blaustein (3 June 1953 - 24 June 2020)}

The eminent freshwater ecologist Leon Blaustein died peacefully at his home in Koronit, Israel during the night of June 23/24, 2020. A native of New Jersey in the United States, Leon obtained both his bachelor's (1975) and master's (1978) degrees from Rutgers University. He always felt close to Rutgers, and had many short and long visits there, including a Sabbatical in 2005. He obtained his Ph.D. in Ecology in 1988 from the University of California at Davis, followed by two postdocs at Ben-Gurion University in southern Israel. Leon then headed north to the University of Haifa in Israel, where he remained for his academic career. Leon steadily advanced at the University of Haifa, becoming a Full Professor in the Department of Evolutionary and Environmental Biology, Head of the Community Ecology Laboratory, a Fellow of the Institute of Evolution, the Director of the Kadas Green Roofs Ecology Research Center and the Editor-in-Chief of the $I s$ rael Journal of Ecology and Evolution.

Most of Leon's research focused on two groups of organisms: mosquitoes and salamanders. He approached his studies on these animals in a multi-disciplinary fashion. Leon studied behavior, population and community ecology, population genetics, and transcriptomics. He executed both laboratory and field experiments. He particularly excelled at experimental design, both in the lab and in the field. Field trips with Leon were always a delight. He had an excellent naturalist's eye, and delighted in sharing his discoveries with everyone. He was curious about everything he saw, and his knowledge of natural history was broad and deep and not at all limited to the organisms he studied. (The one exception was birds, as he classified all birds as "pigeons".) This broad knowledge did deepen his research as he noted subtle aspects of the environment that could impact his focal species. These experiments and field studies produced insight and major contributions to amphibian ecology and evolution, mosquito population regulation, compassionate conservation, biodiversity conservation, and - late in his career - green roof ecology.

Leon's final project on the endangered species Salamandra infraimmaculta illustrates well the breadth of his approaches and his drive to learn all about his study system rather than one narrow aspect. This project focused on plasticity in aquatic resource use in this species at its southernmost boundary. The southernmost part of this species' range is in northern Israel; indeed, this represents the southernmost range for the entire genus Salamandra. Moreover, this species prefers higher altitudes. In this era of climate change, populations at the low latitude boundaries of a species, particularly ones that prefer higher altitudes, are the ones most at risk. Hence, his extensive work on this species has great importance for conservation and timeliness. Moreover, the role of plasticity in shaping a species' response to climate change has not been studied extensively. This project was feasible only because of Leon's extensive earlier work on the breeding sites, larviposition behavior, and larval survival in this species. Most salamanders specialize in the type of aquatic habitat they use for their larval phase, but $S$. infraimmaculta does not. This species can use perma- 
nent ponds and springs; permanent and seasonal streams; as well as rock pools that fill with rain water for only a few months of the year. Leon assembled a diverse team of graduate students, post-docs, and collaborators to address this system from multiple directions. Leon first sought to define the evolutionary and ecological context in which this plasticity is manifest. Leon and his group performed molecular surveys of genetic diversity, maximum entropy modelling of habitat data to determine optimal and suboptimal areas, and phylogeographic analyses to uncover historical effects. His group performed mark/recapture studies to estimate adult population sizes in a diversity of habitats. These studies revealed that this southernmost boundary itself was very diverse genetically and ecologically, varying from areas of optimal habitat with high levels of genetic diversity and gene flow to areas of marginal habitat that were subdivided genetically. Moreover, they discovered Mt. Carmel to be an area of optimal habitat that was an historical isolate with a severe reduction in genetic diversity due to a past founder event. Field and laboratory experiments on larval developmental and morphological plasticity as well as on their transcriptomes revealed that plasticity at both the organismal level and the transcriptome levels showed both genetically based differences among these populations as well as direct individual responsiveness to environmental variation. Coupling climate projection models with the maximum entropy models revealed diverse conservation challenges in these different areas of the southernmost boundary. Hence, both the evolvability of plasticity and current individual environmental plasticity could play an important role in the survival of this endangered species.

As this example illustrates, Leon was concerned about the big picture but without ignoring the details that make the big picture credible. Sometimes these details could raise Leon's concern about more local pictures, particularly if they were of conservation importance. A road in the Upper Galilee had been improved, and $2 \mathrm{~km}$ of this road ran next to a stream used by the salamanders. A graduate student, Iftah Sinai, noticed many dead adults on the road after rainy nights in the winter, exactly the conditions under which the adult salamanders move and disperse. Discussions with Leon and others in the lab lead to this section of the road being an additional study in which road kills were monitored after every rainy night for 4 years. In addition, mark/recapture studies were executed, and a local maximum entropy analysis was performed. This work showed that as traffic increased, so did the proportion of the adult population killed on the road, and that specific sections of the road were at highest risk. Specific recommendations were made to reduce this road-kill mortality. Leon was greatly concerned about compassionate conservation in general, and the salamander project proceeded because non-lethal sampling protocols were developed and all animals were returned to their sites of capture after sampling or use in laboratory experiments.

Leon's concern for the environment was also reflected in his becoming the first director of the Kadas Green Roofs Ecology Research Center, established by a generous donation by the Kadas family. Leon built this research center literally out of nothing - carving out lab and office space, hiring technicians and recruiting graduate students, and establishing several green roof experimental plots on buildings scattered around the campus of the University of Haifa. He was heavily involved in designing these experiments, but unfortunately his progressing frontal lobe degeneration reduced his ability to supervise this work before many of these experiments could be completed. Nevertheless, the establishment of the Kadas Green Roofs Ecology Research Center stands as a continuing legacy of both the Kadas family and Leon.

This diversity of research topics was reflected in a large and diverse lab group, with many technicians, graduate students, post-docs, and collaborators. Leon was a rigorous mentor and col- 


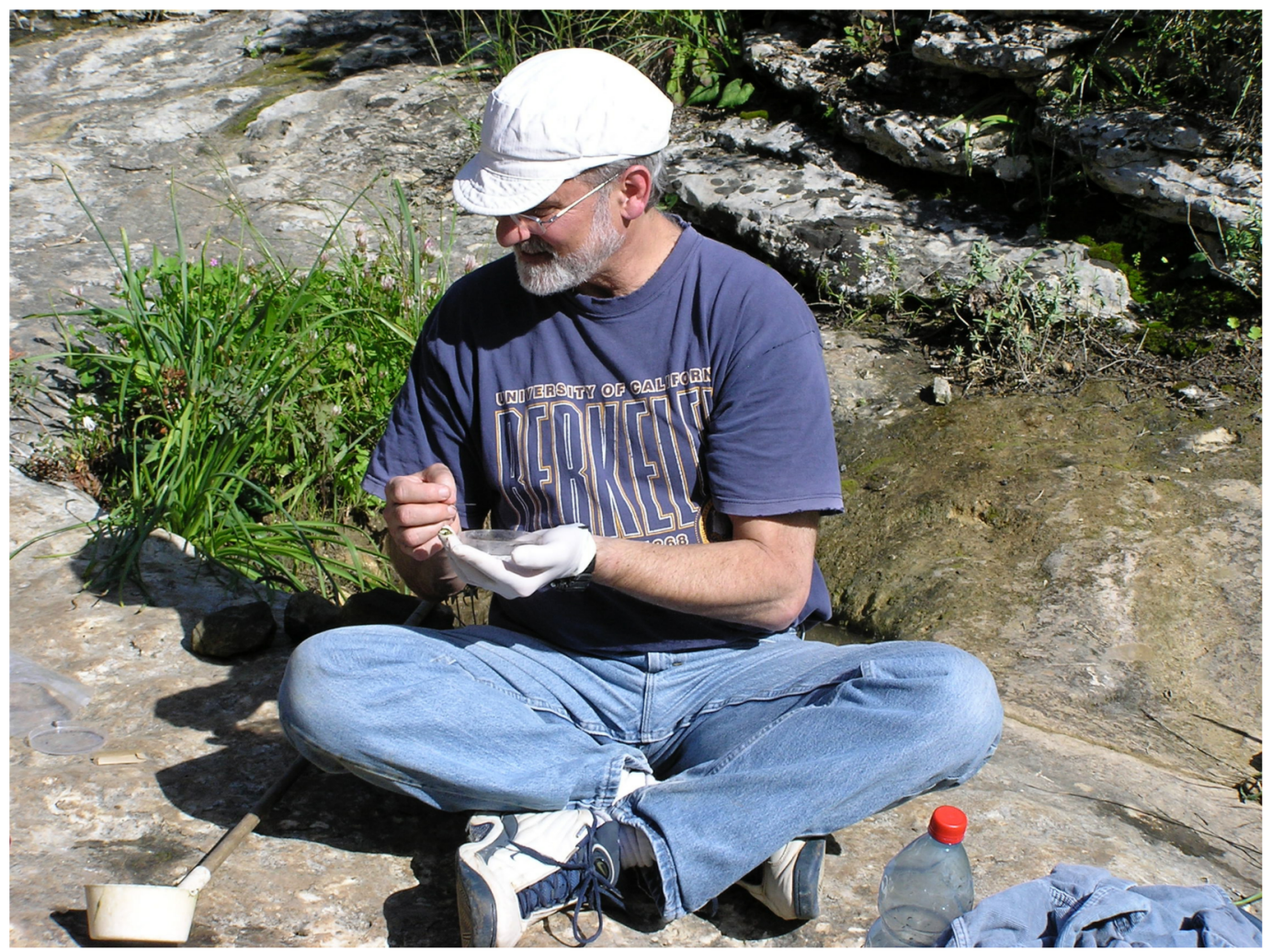

Figure 1. Leon Blaustein in the field in Mt. Carmel, Israel, in March 2007, processing larva samples of Salamandra infraimmaculata.

laborator, but he did so with friendliness, helpfulness, and caring seasoned by much humor. The resulting atmosphere in his lab was characterized by comradery, much interaction, creativity, and productivity. Working in his lab was simply a lot of fun. Leon interacted with everyone in an outgoing, caring manner that was always tinged with his unique sense of humor. Everyone in the lab, from technicians to visiting collaborators, were assigned a nickname. Leon's self-assigned nickname was "LeBron" (from the basketball player LeBron James) that indicated his love and passion for his weekly basketball games with others at the University of Haifa. Leon did not claim that he had the same skills as the other LeBron, but he did say that his game trash-talking skills were second to none. Leon also liked a nickname that I gave him. On a field trip to the Lower Galilee to collect salamander larvae from rock pools, I lost my cell phone. Leon and I looked for the phone, but it seemed a hopeless task in the rugged countryside. As dusk descended upon us, I gave up all hope, when Leon announced that he used the force to find the phone - and he pointed to it on the ground. After that I called him "Jedi Master", and he certainly was the Jedi Master of the forces of generosity, compassion, kindness, and friendship. Few people have mastered these forces as thoroughly as Jedi Master Leon. Leon treated all people with these attributes of friendliness, respect, and concern. In addition to his extensive knowledge of amphibian breeding sites in the Galilee, Leon also had extensive knowledge of the best hummus restaurants in the Arab villages of the Galilee. He was always greeted and hugged by the owner, and no matter how crowded, a table was made for Leon and his guests. Leon was not just known by many people of all stations, he was beloved. I also 
witnessed this love at the university. As Leon's cognitive functions declined and he could no longer function as a faculty member, he still loved coming to the university. We would often go to visit others and get food and coffee. As we wandered the halls, I was impressed by the large number of people who would come up to greet him. Once, Leon's favorite coffee place was extremely crowded, but we ordered anyway, anticipating a long wait for our coffee. However, Leon immediately went to the counter where people picked up their orders and grabbed the nearest coffee cup. The manager gently told "LeBron" that this was not his coffee, but he would personally make his coffee immediately, which he did. Later, when Leon could no longer visit the university, I got coffee at this place and the manager asked me about "LeBron". As I told him, he was visibly upset about Leon's declining health. Leon treated everyone in a friendly and good-humored fashion, at this was returned by all who knew him.
As Leon's disease progressed, he stayed in his home at Koronit, a mountain-top village in the Lower Galilee. Although his two grown children no longer lived there, they frequently visited, so he was with the family that he loved and cared for. He also had many other visitors, and enjoyed walking around Koronit. Even when he could no longer talk, he remained very observant on these walks, taking great delight in seeing lizards, hyraxes, birds, insects, and flowers. He also would share his delight at these discoveries, smiling and pointing at them so the people with him could see. Leon lost much to his disease, but his core remained untouched: a love for nature, and sharing that love with others. I miss him greatly.

Alan R. Templeton (Department of Biology, Washington University, St. Louis, MO 63130-4899, USA) 